\title{
Coating induced corrosion of coronary stents - A comparative study with clinical consequences
}

\author{
Lucila Navarro', Gustavo Duffó ${ }^{2}$, David Vetcher ${ }^{3}$, Victor P Moles ${ }^{4}$, Julio A Luna ${ }^{1}$ and Ignacio Rintoul ${ }^{1 *}$ \\ ${ }^{1}$ Consejo Nacional de Investigaciones Científicas y Técnicas. Universidad Nacional del Litoral. Santa Fe, Argentina \\ ${ }^{2}$ Comisión Nacional de Energía Atómica, Consejo Nacional de Investigaciones Científicas y Técnicas. Universidad Nacional de San Martín. Buenos Aires, Argentina \\ ${ }^{3}$ Bioimagen, Paraná, Argentina \\ ${ }^{4}$ Unidad de Intervenciones Cardiovasculares, Santa Fe, Argentina
}

\begin{abstract}
The clinical fails of gold ( $\mathrm{Au}$ ) and carbon (C) coated 316LSS stents have been barely investigated. A comprehensive understanding of these fails may contribute to the improvement of protocols for the development of better materials and surfaces. This work elucidates the reasons of the clinical fails of Au and C coated 316LSS stents, demonstrates the physical-chemical processes that leaded to these fails, reviews the mistaken line of thought that pushed these technologies to the most advanced clinical stages and proposes complementary techniques to the FDA guidances for the early non-clinical engineering tests. Au and C coated 316LSS, baremetal 316LSS and Co-Cr stents were studied using potentiodynamic scans according to FDA guidance protocols, image analysis and bulk elemental composition. The statistical clinical outcome of the stents was found to correlate with the ions release patterns eluted from their corresponding metallic substrates. In all cases ions release were consequence of post-passive corrosion processes such as pitting corrosion of 316LSS and bulk grain dissolution of Co-Cr alloy. Surprisingly, the stents outcome did not correlate with their corresponding corrosion rates. Clinical fails of Au and C coated 316LSS stents are explained in terms of their fails to inhibit the ions release from their 316LSS substrates. Materials and surface improvements must be oriented to inhibit post-passive corrosion processes of stents substrates. Potentiodynamic scans complemented with image analysis are strongly recommended for the evaluation of pre-clinical engineering tests.
\end{abstract}

\begin{abstract}
Abbreviations: 316LSS: AISI 316L stainless steel; SCE: Saturated calomel electrode; $\mathbf{V}_{\mathrm{SCE}}$ : Volts respect to SCE; E: potential in $\mathrm{V}_{\mathrm{SCE}}$; : Current in amperes; Er: Rest potential in $\mathrm{V}_{\mathrm{SCE}}$; Eb: Critical breakdown potential in in $\mathrm{V}_{\mathrm{SCE}}$; Ecor: Corrosion potential in $\mathrm{V}_{\mathrm{SCE}}$; Icor: Corrosion current density in amperes $\mathrm{cm}^{-2}$; CR: Corrosion rate in $\mathrm{mm}_{\text {year }}$.
\end{abstract}

\section{Introduction}

Each year, nearly 1.4 million stents are implanted worldwide [1]. The majority of implanted stents are made of AISI 316L stainless steel (316LSS) and cobalt-chromium (Co-Cr) alloy [2]. Their excellent mechanical properties and corrosion resistance are the reasons for their prevalence $[3,4]$. However, they present some limitations including restenosis and thrombosis $[5,6]$. The corrosion of these alloys plays an important role on the implants outcome [3,7,8]. Corrosion processes release toxic ions to the surrounding tissues changing the chemistry at the implant zone, promoting an overgrowth of endothelial cells, activating the immune cells and ultimately giving rise to an inflammatory response and restenosis [9]. Contact allergy to metal ions has been suggested to contribute to restenosis throw inflammation and release of chemotactic and growth factors [10]. Corrosion also affects the integrity of the implant. Stent fracture due to corrosion has been detected in 1-3\% of coronary cases [11] and has been associated to platelet activation, stent thrombosis and neointimal growth with upregulation of proinflammatory factors [12].

Metal ions toxicity has been reviewed in a solid bibliographic work [13]. This report concludes that ions toxicity depends on the chemical composition of the alloy, the surface condition, the size and dimensions of the implant, the releasing time, the oxidation state of released ions and the synergistic effects between the ions. Moreover, the toxicity rank for the main ions released from 316LSS and Co-Cr alloys was reported as: $\mathrm{Cr}^{+6}>\mathrm{Ni}^{+2}>\mathrm{Cr}^{+3}>\mathrm{Co}^{+3}>\mathrm{Fe}^{+3}$.

A variety of materials have been used as coating for cardiovascular metallic stents [14]. These materials are intended to improve the biocompatibility of the stents by preventing ions release from their surface.

The majority of these coatings did not pass the research stages, a few were moved to clinical trials and very few were finally approved by regulatory agencies and allowed to be industrially manufactured and globally marketed. Gold ( $\mathrm{Au})$ and carbon $(\mathrm{C})$ coated 316LSS stents are cases of study. They passed all research stages, they were approved by the World's most exigent regulatory agencies and they were industrially manufactured and globally marketed. However, after an enthusiastic initial period, $\mathrm{Au}$ and $\mathrm{C}$ coated stents were abandoned due to their poor clinical results.

The reasons for the clinical fails of $\mathrm{Au}$ and $\mathrm{C}$ coated stents were barely investigated and quickly condemned to oblivion even after been responsible for enormous expenses in research, trials, intellectual

${ }^{*}$ Correspondence to: Ignacio Rintoul. INTEC CCT-CONICET Santa Fe. Ruta Nacional. 168. El Pozo. CP 3000. Santa Fe, Argentina, Tel: +54 3425412 146; Fax: +54 342 4511079; E-mail: irintoul@santafe-conicet.gov.ar

Key words: allergy, biocompatibility, biomaterial, corrosion, implant, stainless steel.

Received: December 17, 2019; Accepted: January 21, 2020; Published: January 24,2020 
property development, market launches and ultimately disabilityadjusted life years associated to the implantation of $\mathrm{Au}$ and $\mathrm{C}$ coated stents when compared against bare-metal stents made of 316LSS and Co-Cr.

$\mathrm{Au}$ has high corrosion resistance and high fluoroscopic visibility [15]. Au coated stents were widely used in coronary stenting procedures. Animal studies suggested that Au might reduce thrombosis due to its inertness, low platelet adhesion and low thrombus formation [16]. However, a significant increment of the restenosis rate associated to implanted Au coated stents was confirmed in comparative clinical trials against bare-metal stents [17-19]. Despite proving excellent corrosion behavior, Au coated stents resulted with high rates of restenosis [20]. Delamination of the Au coating, further exposition of the 316LSS substrate to the physiological medium and ultimate ion release due to corrosion of the implant were proposed to explain the poor outcome of Au coated stents [21]. Another studies revealed very high concentration of $\mathrm{Au}$ in the blood of patients implanted with $\mathrm{Au}$ coated stents when compared against patients implanted with Nitinol stents. Additionally, these studies established a correlation between the high levels of $\mathrm{Au}$ in blood with contact allergy reaction to this metal [10,22]. Au dissolution, $\mathrm{Au}$ ions diffusion and/or dispersion of Au coating debris were hypothesized to be the reasons to explain the contact allergy reactions and the high levels of $\mathrm{Au}$ in the body [23].

$\mathrm{C}$ is a inert material used for stent coating in the past. Pre-clinical trials of $\mathrm{C}$ coated Nitinol stent showed the absence of mural thrombi, low inflammatory response and early endothelialization [24]. C coated $316 \mathrm{LSS}$ stents reduced the restenosis rate to $11 \%$ [25]. However, these results were not consistent with other studies. A comparative study between bare-metal 316LSS stents and C coated 316LSS stents showed that the $\mathrm{C}$ coating did not influence the inflammatory response of the implants [26,27]. Another study also documented comparable restenosis rate and major adverse events between bare-metal 316LSS stent and C coated 316LSS stents [28].

After their clinical fails $\mathrm{Au}$ and $\mathrm{C}$ coated stents were retired from the market. Furthermore, little and highly speculative analysis on the understanding of why $\mathrm{Au}$ and $\mathrm{C}$ coated stents failed in reducing restenosis rate has been done. The aim of this contribution is to elucidate the technical reasons of the clinical fails of $\mathrm{Au}$ and $\mathrm{C}$ coated stents. The paper also discuss and criticize the actual protocols for materials and processes development for stent coatings. Finally, we propose new, fast, easy and cheap in-vitro protocol to test the performance of coatings deposited over metallic stents before its derivation to clinical trials.

\section{Materials and methods}

Coronary stents made of 316LSS and Co-Cr alloy (Aeromedical, Argentina), Au coated 316LSS stents (Inflow Gold Flex System, Inflow Dynamics) and C coated 316LSS stents (Carbonfilm ${ }^{T M}$ Coated Coronary Stent. Sorin Biomedical) were used as case materials. Sodium chloride, potassium chloride, monosodium phosphate and potassium phosphate dibasic (Anedra, Argentina) were used to prepare phosphate-buffered saline solution (PBS).

An optical microscope (OM) Leica DM 2500 M (Leica Microsystems, Germany) powered with Leica Application Suite Version 2.8.1. software and a scanning electron microscope (SEM) (JEOL JSM-35C, USA) operating at $20 \mathrm{kV}$ were used for measuring the area of the stents and for the observation of the structure, integrity and surface of the stents before and after the crimping process and before and after corrosion tests. The area of stents was calculated using a precision image analyzer software (ImageJ Wayne Rasband, USA).
Energy-dispersive X-ray spectroscopy (EDX) analysis was performed using an X-ray microprobe (JEOL, USA) coupled to the SEM and served to evaluate chemical composition of the bulk stent material.

The corrosion susceptibility of the stents were evaluated according to the FDA guidance for non-clinical engineering tests and recommended labeling for intravascular stents [29]. This FDA guidance recommend the use of the ASTM F2129 standard to evaluate the corrosion resistance of the stent [30]. The test consists in a potentiodynamic scan of the stent. The electrochemical system consisted of a conventional three-electrode cell including a working electrode made of a stent, a saturated calomel electrode (SCE) as a reference electrode and a platinum plate as a counter electrode, connected to a potentiostat (Gamry Reference 600, USA). The stents were attached at one end to a copper wire using a conductive silver glue. The wire was inserted in a glass tube and the end of the tube was filled with metallographic epoxy resin to isolate the joint between the stent and the wire from the electrolyte. The electrolytic medium was $\mathrm{PBS}$ at $\mathrm{pH}=7.4$ and $\mathrm{T}=37^{\circ} \mathrm{C}$.

First, the stents were leave under open circuit potential (OCP) condition during two hours to reach their Rest Potential (Er). The potentiodynamic polarization scan $E$ (potential) vs $I$ (current) was performed in the anodic direction from $\operatorname{Er}\left(-100 \mathrm{mV}_{\mathrm{vs} \text { OCP }}\right)$ to $1.4 \mathrm{~V}$ at a scan rate of $0.5 \mathrm{mV} / \mathrm{s}$. The critical breakdown potential $(E b)$ was obtained from the potentiodynamic polarization curves. The corrosion potential (Ecor) and corrosion current density (Icor) were obtained according to Tafel method [31]. Corrosion rate $(C R)$ was calculated according to equation 1 .

\section{$C R=I$ cor $K E W / d \quad$ Eq. 1}

Here, $K$ is a constant depending on units $\left(\mathrm{mm} \mathrm{A}^{-1} \mathrm{~cm}^{-1}\right.$ year $\left.{ }^{-1}\right), E W$ is the equivalent weight $(\mathrm{g})$ and $d$ is the density of the corresponding material $\left(\mathrm{g} \mathrm{cm}^{-3}\right)$. The test were performed by triplicates on unexpanded and expanded stents.

\section{Results}

Figure 1 presents SEM images of the stents. All stents present a smooth surface with no evident defects such burrs and inclusions coming from manufacturing processes. Au and C coated stents presented good coverage without any microscopic imperfection of the coating and no exposed substrate material. EDX analysis of all stents are shown in Table 1.

316LSS stents present an elemental composition according to the ASTM A 240/A 240M specification for 316LSS alloy. The 100\% Au composition evidenced in Au coated 316LSS stents indicates that the thickness of the Au coat is higher than 1 micron. In this case, the highenergy beam of electrons interacts with the upper Au volume part of the coat. The $\mathrm{C}$ coated $316 \mathrm{LSS}$ stents present a 316LSS basic elemental composition with partial substitution of $\mathrm{Fe}, \mathrm{Ni}$ and Mo by Co and $\mathrm{W}$ additions. The $\mathrm{C}$ coating resulted transparent to EDX due to its low atomic weight. Finally, Co-Cr stents present a composition according to the $\mathrm{L} 605 \mathrm{Co}-\mathrm{Cr}$ standard alloy.

Figure 2 presents the stent's OCP time evolution. All stents reached a stable value within the first hour of evaluation. The OCP of $\mathrm{C}$ coated stents exhibited the highest initial value followed by a concave-up decrease. C coated stents reached $E r=-0.2 \mathrm{~V}_{\mathrm{SCE}}$ at 60 minutes. $\mathrm{C}$ coated stents presented the most positive potential meaning that $\mathrm{C}$ promotes a more passive behavior when compared 

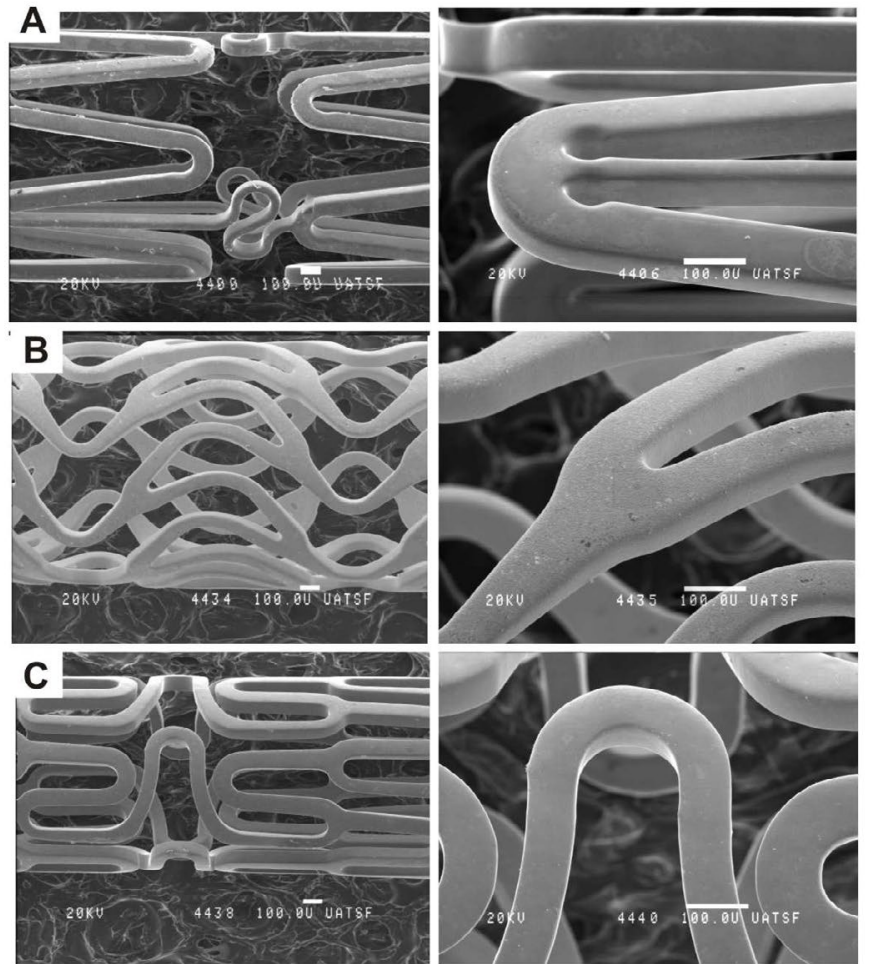

D
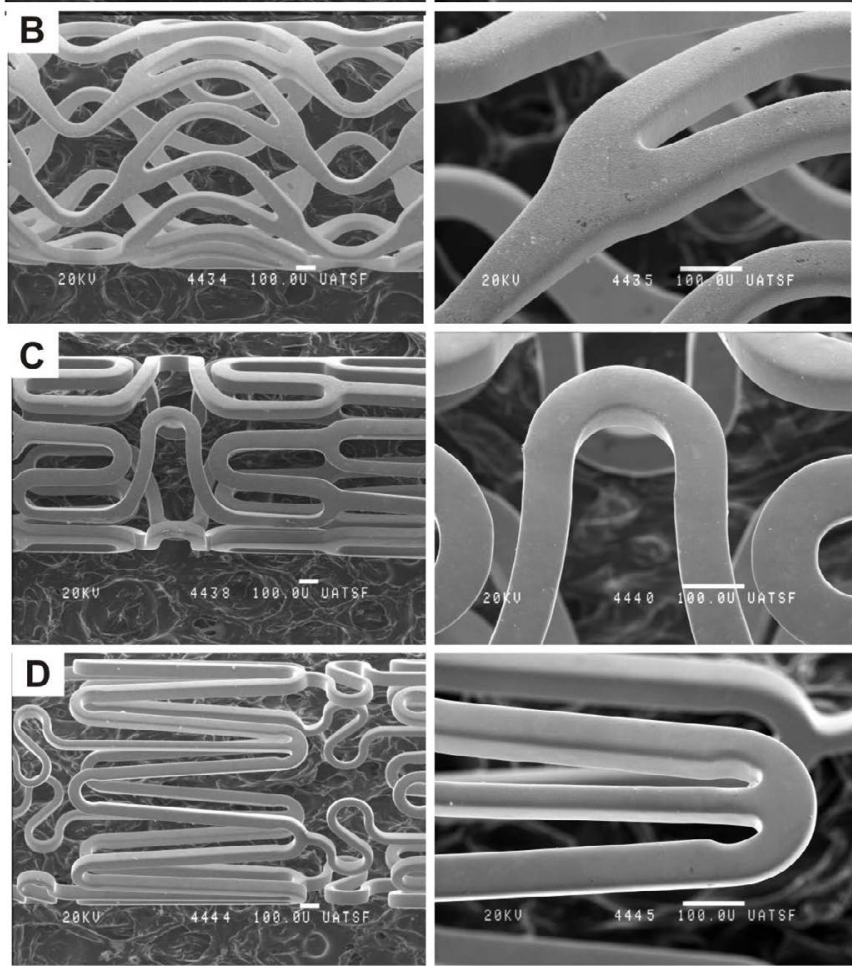

Figure 1. SEM images of stents. A) Bare-metal 316LSS; B) Au coated 316LSS; C) C coated 316LSS; D) Co-Cr alloy

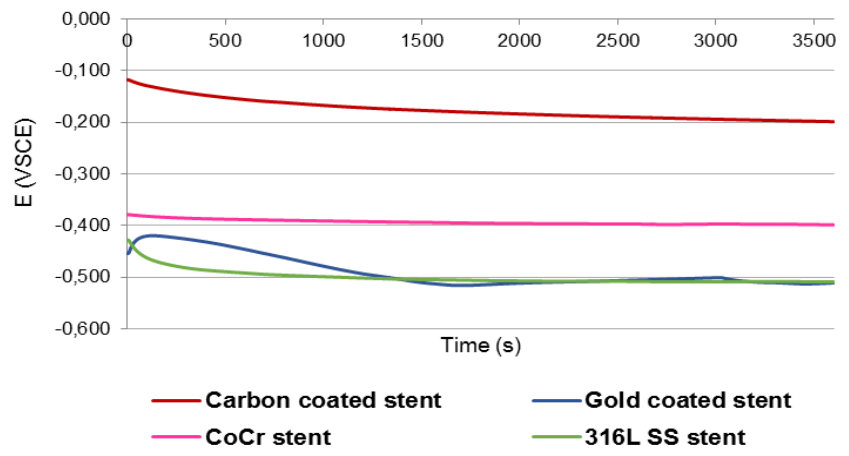

Figure 2. Rest potential of stents

against the other stent materials. The OCP of Co-Cr stents exhibited lower initial value than $\mathrm{C}$ coated stents and followed by a concave-up decrease. Co-Cr stents reached $E r=-0.40 \mathrm{~V}_{\mathrm{SCE}}$ at 30 minutes. The OCP of 316LSS stents exhibited a low initial value followed by a concaveup decrease to the more negative potential zone. 316LSS stents reached $E r=-0.5 \mathrm{~V}_{\mathrm{SCE}}$ at 15 minutes. The OCP of Au coated stents exhibited a low initial value followed by a 2 minutes linear increment and subsequently a linear decrease reaching $E r=-0.5 \mathrm{~V}_{\mathrm{SCE}}$ at 30 minutes. The Au coated and 316LSS stents registered similar Er values.

Figure 3 presents the potentiodynamic scans. The corrosion parameters are depicted in Table 2. 316LSS stents resulted with the highest Icor, Ecor and CR. The shifting from the cathodic behavior to the dissolution zone occurred at $E=-0.38 \mathrm{~V}_{\mathrm{SCE}}$. The material showed a passive behavior within $-0.23 \mathrm{~V}_{\mathrm{SCE}}<E<0.48 \mathrm{~V}_{\mathrm{SCE}}$. The breakdown of the passive zone started at $E=0.48 \mathrm{~V}_{\mathrm{SCE}}$ and $I$ sharply increased at $E>0.62 \mathrm{~V}_{\mathrm{SCE}}$. The scans corresponding to Au and C coated 316LSS stents and CoCr stents are shifted to lower $I$ values when compared to bare-metal 316LSS stents. Au coated stents resulted with the lowest $C R$ and Ecor, and high $E b$. Au coated 316LSS stents presented a CR 2515 times lower than bare-metal 316LSS stents.

The shifting from the cathodic behavior to the active dissolution zone occurred at $E=-0.62 \mathrm{~V}_{\mathrm{SCE}}$. The material showed a proportional increment of $E$ with the increment of $I$ within $-0.62 \mathrm{~V}_{\mathrm{SCE}}<E<0.60 \mathrm{~V}_{\mathrm{SCE}}$ $I$ sharply increased at $E>0.60 \mathrm{~V}_{\mathrm{SCE}}$. The material did not passivate. C coated stents presented potentiodynamic properties between Au coated stents and 316LSS stents. The shifting from the cathodic behavior to the dissolution zone occurred at $E=-0.52 \mathrm{~V}_{\mathrm{SCE}}$. Two passive zones are clearly identified within $-0.40 \mathrm{~V}_{\mathrm{SCE}<} E<-0.25 \mathrm{~V}_{\mathrm{SCE}}$ and $0.41 \mathrm{~V}_{\mathrm{SCE}}<E<0.61 \mathrm{~V}_{\mathrm{SCE}}$ respectively. The second passive zone looks similar to the upper part of the passive zone of bare-metal 316LSS stents. Co-Cr stents presented potentiodynamic properties similar to $\mathrm{Au}$ coated stents

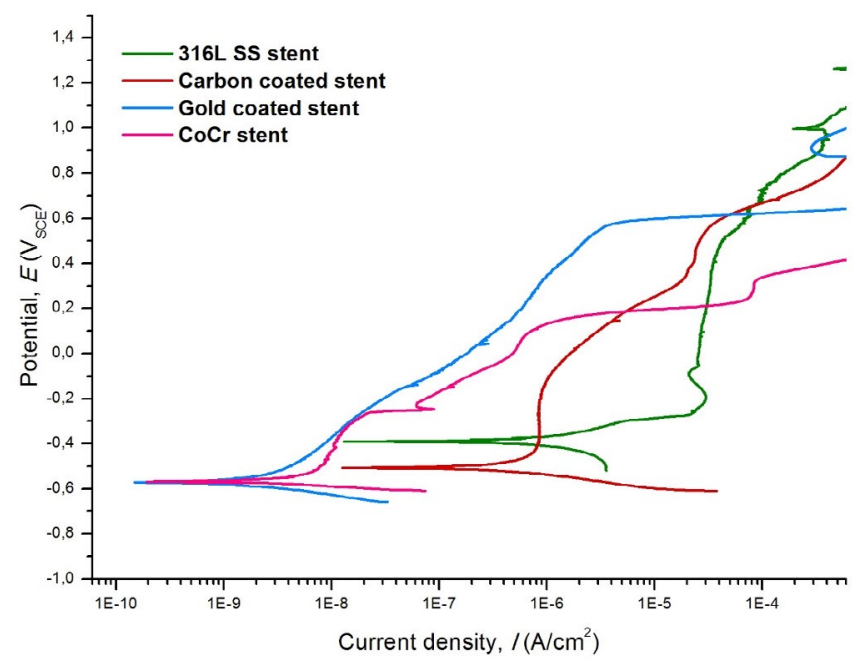

Figure 3. Potentiodynamic scans of stents

Table 1. Elemental composition

\begin{tabular}{|c|c|c|c|c|c|c|c|c|}
\hline Stent & $\mathbf{C r \%}$ & $\mathbf{F e} \%$ & $\mathbf{N i} \%$ & $\mathbf{M o} \%$ & $\mathbf{M n} \%$ & $\mathbf{A u \%}$ & $\mathbf{C o} \%$ & W\% \\
\hline Bare-metal 316LSS & 19.95 & 60.98 & 12.48 & 4.03 & 2.33 & - & - & -- \\
\hline Au coated 316LSS & - & - & - & - & - & 100 & - & \\
\hline C coated 316LSS & 20.48 & 53.80 & 11.76 & 3.08 & 2.31 & - & 6.73 & 1.84 \\
\hline Co-Cr alloy & 23.23 & 2.26 & 9.04 & - & 1.70 & - & 50.21 & 13.55 \\
\hline
\end{tabular}

Table 2. Corrosion parameters

\begin{tabular}{|c|c|c|c|c|}
\hline Parameter & $\begin{array}{c}\text { Bare-metal } \\
316 L S S\end{array}$ & $\begin{array}{c}\text { Au coated } \\
316 L S S\end{array}$ & $\begin{array}{l}C \text { coated } \\
316 L S S\end{array}$ & Co-Cr alloy \\
\hline $\operatorname{Ecor}\left(V_{S C E}\right)$ & $-0.38 \pm 0.01$ & $-0.62 \pm 0.05$ & $-0.52 \pm 0.08$ & $-0.62 \pm 0.02$ \\
\hline $\boldsymbol{E} \boldsymbol{b}\left(V_{S C E}\right)$ & $0.62 \pm 0.08$ & $0.60 \pm 0.01$ & $0.61 \pm 0.07$ & $0.33 \pm 0.04$ \\
\hline $\operatorname{Icor}\left(A / \mathrm{cm}^{2}\right)$ & $1.2 \mathrm{E}-6 \pm 3 \mathrm{E}-7$ & $4.5 \mathrm{E}-9 \pm 6 \mathrm{E}-10$ & $2.2 \mathrm{E}-7 \pm 9 \mathrm{E}-8$ & $1.4 \mathrm{E}-9 \pm 8 \mathrm{E}-10$ \\
\hline CR (mm/year) & $1.7 \mathrm{E}-2 \pm 3 \mathrm{E}-3$ & $6.6 \mathrm{E}-6 \pm 8 \mathrm{E}-10$ & $3.1 \mathrm{E}-3 \pm 9 \mathrm{E}-4$ & $1.3 \mathrm{E}-5 \pm 5 \mathrm{E}-6$ \\
\hline
\end{tabular}


at low $E$. The shifting from the cathodic behavior to the dissolution zone occurred at $E=-0.62 \mathrm{~V}_{\mathrm{SCE}}$. Four passive zones are identified within $-0.50 \mathrm{~V}_{\mathrm{SCE}}<E<-0.24 \mathrm{~V}_{\mathrm{SCE}}, \quad-0.24 \mathrm{~V}_{\mathrm{SCE}}<E<-0.20 \mathrm{~V}_{\mathrm{SCE}}, \quad 0.05 \mathrm{~V}_{\mathrm{SCE}}<E<0.11 \mathrm{~V}_{\mathrm{SCE}}$ and $0.27 \mathrm{~V}_{\mathrm{SCE}}<E<0.33 \mathrm{~V}_{\mathrm{SCE}}$, respectively. I sharply increased when $E>0.33 \mathrm{~V}_{\mathrm{SCE}}$. Co-Cr stents presented the lowest $E b$ in comparison with the rest of the stents.

Figures 4 (a-d) show the surfaces of 316LSS, Au coated, C coated and Co-Cr alloy stents after the electrochemical analysis. 316LSS stents showed pits of all sizes and complete struts dissolution. Au coated stents showed coating delamination and exposition of the $316 \mathrm{LSS}$ substrate. C coated stents revealed coating delamination, exposition of the 316LSS substrate and small pits. Co-Cr stents showed evidence of intragranular corrosion with massive material dissolution.

\section{Discussion}

OM and SEM imaging, EDAX analysis and OCP evaluation resulted according to expected results and confirmed the quality of used materials and the reliability of the characterization techniques.

The stents can be $C R$ ranked as: Au coated $316 \mathrm{LSS}<\mathrm{Co}-\mathrm{Cr}<\mathrm{C}$ coated 316LSS<316LSS bare-metal. Therefore, according to the FDA
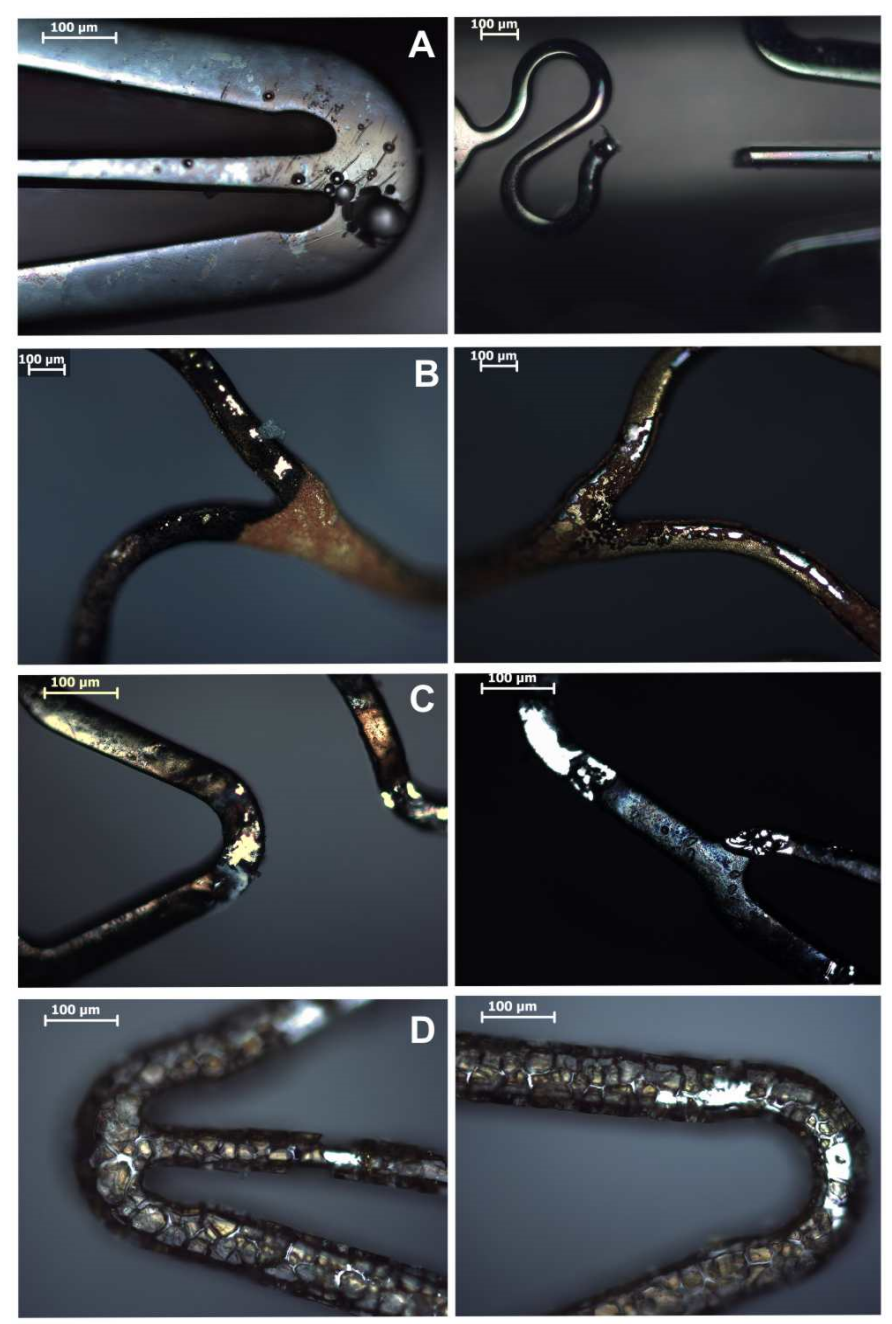

Figure 4. Stent surfaces after electrochemical test. A) Bare-metal 316LSS; B) Au coated 316LSS; C) C coated 316LSS; D) Co-Cr alloy guidances the stents can be corrosion resistance ranked as: 316LSS bare-metal $<\mathrm{C}$ coated $316 \mathrm{LSS}<\mathrm{Co}-\mathrm{Cr}<\mathrm{Au}$ coated 316LSS. But, the clinical evidence revealed the following increasing ranking in restenosis rate: $\mathrm{Cr}-\mathrm{Co}<316 \mathrm{LSS}$ bare-metal $=\mathrm{C}$ coated $316 \mathrm{LSS}<\mathrm{Au}$ coated $316 \mathrm{LSS}$. Herein lies the main issue of discussion. It is evident that a decrease of the stent $C R$ cannot be directly correlated to a decrease of the stent restenosis rate.

The efforts in the attempt of decreasing the restenosis rate were misguidedly oriented in the direction of reducing the $C R$ of the stents material. Taking the 316LSS bare-metal stent as reference material, the $C R$ was successfully reduced 5, 1277 and 2515 times by coating the 316LSS substrate with C, by substituting the 316LSS with Co$\mathrm{Cr}$ alloy and by coating the 316LSS substrate with $\mathrm{Au}$, respectively. Disappointedly, these promising results were not reflected in clinical efficiencies. Therefore, pre-clinical decisions based exclusively on $C R$ values may lead to great clinical fails.

However, potentiodynamic scans complemented with image analysis give valuable information. The effect of C coating on 316LSS stent substrate decreased the $C R$ and promoted the apparition of a C coat based first passive zone. When this coating was breached, the 316LSS substrate resulted exposed, I rapidly increased and the C coated 316LSS stent tended to match the electrochemical behavior of the 316LSS baremetal stent. The passivation of the exposed 316LSS stent substrate is identified as the second passive zone located in the upper part of the potentiodynamic scan. Moreover, the breakdown of the second passive zone of the $C$ coated 316LSS stents and the passive zone of the 316LSS bare-metal stents occurred at similar $E b$ and $I$. Moreover, in both cases, the breakdown of the passive zones resulted in pitting corrosion of the 316LSS material. The substitution of 316LSS bare-metal stent by Co-Cr bare-metal stent decreased the $C R$ and promoted the apparition of four passive zones. These passive zones probably correspond to the formation of complex oxides based on $\mathrm{Cr}^{+2}, \mathrm{Cr}^{+3}, \mathrm{Cr}^{+4}$ and $\mathrm{Cr}^{+6}$. Interestingly, the last passive zone breakdown at the lowest $E b$ among the studied stents and at similar $I$ than C coated 316LSS stent and 316LSS bare-metal stent. Image analysis suggests different chemical composition, and thus dissolution rate, between the bulk and the border of the Co-Cr metallic grains of the alloy. Such chemical segregation is common in $\mathrm{Cr}$ alloys and in most of the cases it is a consequence of heat treatments. In Co-Cr stents, chemical segregation can be the consequence of the heat treatment suffered by the alloy during the laser cut manufacturing process. Finally, the effect of Au coating on 316LSS stent decreased the $C R$. Apparently, the Au coating dissolves gradually with proportional increment of $E$ and $I$. This gradual dissolution process explains the high levels of Au found in patients implanted with Au coated stents. When the Au coating eventually breached, the 316LSS substrate resulted exposed, and $I$ sharply increased at $E b$ similar to the $E b$ observed for $\mathrm{C}$ coated 316LSS stents and 316LSS bare-metal stents. Moreover, the breakdown of the Au coating also resulted in pitting corrosion of the 316LSS substrate.

It is evident that restenosis rate is more related to the toxicity of released metal ions than to the $C R$. The higher the toxicity of the released ions is, the higher the restenosis rate will be. Co-Cr stents have lower restenosis rate than 316LSS stents. Evidently, the grain dissolution of the $\mathrm{Co}-\mathrm{Cr}$ alloy releases less toxic corrosion products than the pitting corrosion process of 316 LSS. This result can be explained in terms of the total amount and oxidation states of the ions released from the 316LSS and Co-Cr alloys after the breakdown of their corresponding passives zones. In both cases, the breakdown of passives zones occurred at $I=1$ E-4 $\mathrm{A} \mathrm{cm}^{-2}$. This amount can be transformed to $1.036 \mathrm{E}-9 \mathrm{e}^{-} \mathrm{mols} \mathrm{cm} \mathrm{cm}^{-2} \mathrm{~s}^{-1}$ 
Table 3. Alloy and corrosion product composition for $I=1 \mathrm{E}-4 \mathrm{~A} \mathrm{~cm}^{-2}$

\begin{tabular}{|c|c|c|c|c|c|c|}
\hline & \multicolumn{2}{|c|}{ Co-Cr alloy stent } & \multicolumn{2}{c|}{$\begin{array}{c}\text { Bare-metal 316LSS } \\
\text { stent }\end{array}$} & \multicolumn{2}{c|}{ C coated 316LSS stent } \\
\hline & $\begin{array}{c}\text { Bulk } \\
\text { Mol\% }\end{array}$ & $\begin{array}{c}\text { Released } \\
\text { ions }\end{array}$ & $\begin{array}{c}\text { Bulk } \\
\text { Mol\% }\end{array}$ & $\begin{array}{c}\text { Released } \\
\text { ions }\end{array}$ & $\begin{array}{c}\text { Bulk } \\
\text { Mol\% }\end{array}$ & $\begin{array}{c}\text { Released } \\
\text { ions }\end{array}$ \\
\hline $\boldsymbol{C r}$ & 27.96 & $7.32 \mathrm{E}-11$ & 21.59 & $6.04 \mathrm{E}-11$ & 22.43 & $6.24 \mathrm{E}-11$ \\
\hline $\boldsymbol{F e}$ & 2.53 & $6.63 \mathrm{E}-12$ & 61.45 & $1.72 \mathrm{E}-10$ & 54.86 & $1.53 \mathrm{E}-10$ \\
\hline $\boldsymbol{N i}$ & 9.64 & $2.52 \mathrm{E}-11$ & 11.97 & $3.35 \mathrm{E}-11$ & 11.41 & $3.17 \mathrm{E}-11$ \\
\hline $\boldsymbol{M o}$ & - & - & 2.36 & $6.61 \mathrm{E}-12$ & 1.83 & $5.08 \mathrm{E}-12$ \\
\hline $\boldsymbol{M n}$ & 1.95 & $5.10 \mathrm{E}-12$ & 2.62 & $7.34 \mathrm{E}-12$ & 2.39 & $6.66 \mathrm{E}-12$ \\
\hline $\boldsymbol{C o}$ & 53.31 & $1.40 \mathrm{E}-10$ & - & - & - & - \\
\hline $\boldsymbol{W}$ & 4.61 & $1.21 \mathrm{E}-11$ & - & - & 6.50 & $1.81 \mathrm{E}-11$ \\
\hline others & 0.00 & - & 0.01 & - & 0.58 & - \\
\hline
\end{tabular}

by using the definition of Coulomb and the Faraday constant. The total amount of electrons evolved from the system must be balanced with an equal amount of positive charges provided by the released ions. The oxidation states of the ions can be assumed according to the literature data presented in the introduction. Image analysis suggested that the ion release composition of 316LSS and Co-Cr alloys must be equal, or very similar, to their corresponding bulk alloy compositions.

Pitting corrosion of 316LSS generated pits through the bulk material and the dissolution of the Co-Cr progressed through the bulk grain of the alloy. Finally, the released ion composition and quantity for 316LSS and Co-Cr alloy in post-passive breakdown corrosion conditions at $I=1 \mathrm{E}-4 \mathrm{~A} \mathrm{~cm}^{-2}$ is summarized in Table 3.

Clearly, stents made of Co-Cr alloy releases $21,14 \%$ more $\mathrm{Cr}$ ions and $24,64 \%$ less $\mathrm{Ni}$ ions than stents made of bare-metal 316LSS. The changes in the type and quantity of the other ions are not as significant as the changes in $\mathrm{Cr}$ and $\mathrm{Ni}$ ions. The great reduction of $\mathrm{Ni}$ ions released from the Co-Cr stents may justify its statistically lower restenosis rate when compared against bare-metal 316LSS stents.

C coated 316LSS stents release 3,15\% more Cr ions and 5,51\% less $\mathrm{Ni}$ ions than bare-metal 316LSS stents. These small differences may justify their statistically similar restenosis rates. The changes in the type and quantity of the other ions do not have an evident effect on the restenosis rate.

Finally, the potentiondynamic scans confirmed the release of great amounts of $\mathrm{Au}$ from Au coated 316LSS stents. Additionally, the release of $\mathrm{Cr}$ and $\mathrm{Ni}$ ions can be assumed similar to those evidenced for baremetal 316LSS stents and C coated 316LSS stents. Here, the presence of $\mathrm{Au}$ ions, its associated allergy to arterial tissues and probably synergistic toxic effect with $\mathrm{Cr}$ and $\mathrm{Ni}$ ions may justify its statistically higher restenosis rate when compared against bare-metal 316LSS stents.

These findings suggest the use of image analysis as crucial complement to the ASTM F2129 standard. Image analysis permits the evaluation of initial surface conditions of the stents, early detection of surface coating defects and the morphology and extent of corrosion. The above exposed correlation between the amount of released ions to the statistical restenosis rate of different stents resulted from the image based confirmation of pitting corrosion and grain bulk dissolution of the 316LSS and Co-Cr alloy stent substrates. This confirmation allowed to assume the composition of released corrosion products to be equal to the alloy composition of the stent substrates.

\section{Conclusions}

The clinical fails of Au and C coated 316LSS stents were associated to the fails of the $\mathrm{Au}$ and $\mathrm{C}$ coats in impairing the pitting corrosion of the 316LSS stent substrate and thus its consequent release of toxic ions to physiologic media. The statistically similar outcome of $\mathrm{C}$ coated 316LSS stents and bare-metal 316LSS stents was associated to similar ion composition of corrosion products derived from similar development of pitting corrosion processes in their 316LSS substrates. The high restenosis rate of Au coated 316LSS stents was associated to the dissolution of the Au coating and a synergistic toxic effect of Au ions with the ion composition of corrosion products coming from pitting corrosion processes of the 316LSS substrate. And the low restenosis rate of Co-Cr stents was associated to a significant decrease of the amount of $\mathrm{Ni}$ ions released from the Co-Cr alloy when compared against 316LSS.

A decrease in the corrosion rate of 316LSS stents can not be directly associated to a decrease its restenosis rate. However, the technical evidence strongly suggest that a decrease or inhibition of $\mathrm{Ni}$ ion release from 316LSS stent substrates will reduce significantly its restenosis rate. $\mathrm{Ni}$ ion release can be reduced or inhibited by impairing the pitting corrosion process of 316LSS stent substrates or by changing the stent substrate by alloys with lower Ni content.

The application of the ASTM F2129 standard as FDA guidance for pre-clinical engineering tests with complementary image analysis is strongly recommended for the evaluation of stents pre-clinical engineering tests.

\section{Declarations}

\section{Authorship}

Lucila Navarro and Gustavo Duffó performed the experiments and drafted the article, David Vetcher and Victor Moles did the analysis and interpretation of data in terms of restenosis phenomena, Julio A. Luna and Ignacio Rintoul did substantial contributions to conception and design of the article, revised the article critically for important intellectual content, did the final approval of the version to be published and act as guarantor of the work.

\section{Funding information}

This work was funded by the Consejo Nacional de Investigaciones Científicas y Técnicas, the Fundación VINTEC and the Unidad de Intervenciones Cardiovasculares.

\section{Competing interests}

The authors declare that they have no competing interests.

\section{References}

1. Mathers C, Fat DM, Boerma JT (2008) The global burden of disease: 2004 update. Switzerland: WHO Press, World Health Organization.

2. Kereiakes DJ, Cox DA, Hermiller JB, Midei MG, Bachinsky WB, et al. (2003) Usefulness of a cobalt chromium coronary stent alloy. Am J Cardiol 92: 463-466. [Crossref]

3. Okazaki Y, Gotoh E (2008) Metal release from stainless steel, $\mathrm{Co}-\mathrm{Cr}-\mathrm{Mo}-\mathrm{Ni}-\mathrm{Fe}$ and $\mathrm{Ni}-\mathrm{Ti}$ alloys in vascular implants. Corros Sci 50: 3429-3438.

4. Bhatia SK (2010) Biomaterials for clinical applications. New York, NY: SpringerVerlag New York.

5. Miller JM, Ohman EM, Moliterno DJ, Califf RM (1999) Restenosis. The clinical issues. In: Topol EJ, editor. Textbook of Interventional Cardiology 3rd ed. Philadelphia: W.B. Saunders, pp: 393.

6. Holmes DR Jr, Kereiakes DJ, Garg S, Serruys PW, Dehmer GJ, et al. (2010) Stent thrombosis. J Am Coll Cardiol 56: 1357-1365. [Crossref]

7. Sojitra P, Engineer C, Kothwala D, Raval A, Kotadia H, et al. (2010) Electropolishing of $316 \mathrm{LVM}$ stainless steel cardiovascular stents: An investigation of material removal, surface roughness and corrosion behaviour. Trends Biomater Artif Organs 23: $115-121$. 
8. Tomizawa Y, Hanawa T, Kuroda D, Nishida H, Endo M (2006) Corrosion of stainless steel sternal wire after long-term implantation. J Artif Organs 9: 61-66. [Crossref]

9. Halwani DO, Anderson PG, Lemons JE, Jordan WD, Anayiotos AS, et al. (2010) Invivo corrosion and local release of metallic ions from vascular stents into surrounding tissue. J Invasive Cardiol 22: 528-535. [Crossref]

10. Svedman C, Möller H, Gustavsson CG, Bruze M (2011) Coronary restenosis and contact allergy to stent material. J Invasive Cardiol 23: E94. [Crossref]

11. Scheinert D, Scheinert S, Sax J, Piorkowski C, Bräunlich S, et al. (2005) Prevalence and clinical impact of stent fractures after femoropopliteal stenting. J Am Coll Cardiol 45: 312-315. [Crossref]

12. Chakravarty T, White AJ, Buch M, Naik H, Doctor N, et al. (2010) Meta-analysis of incidence, clinical characteristics and implications of stent fracture. Am J Cardiol 106: 1075-1080. [Crossref]

13. Obata A, Kasuga T (2015) Cytotoxicity of metallic biomaterials. In: Niinomi M, Narushima T, Nakai M, editors. Advances in metallic biomaterials, Berlin: SpringerVerlag, pp: 323-348.

14. Navarro L, Luna J, Rintoul I (2017) Surface conditioning of cardiovascular 316L stainless steel: A review. Surf Rev Lett 24: 1730002.

15. Hehrlein C, Zimmermann M, Metz J, Ensinger W, Kubler W (1995) Influence of surface texture and charge on the biocompatibility of endovascular stents. Coron Artery Dis 6: 581-586.

16. Serruys PW, Kutryk MJ (2011) Handbook of coronary stents. 4 th ed. CRC press.

17. George CJ, Baim DS, Brinker JA, Fischman DL, Goldberg S, et al. (1998) One-year follow-up of the Stent Restenosis (STRESS I) Study. Am J Cardiol 81: 860-865. [Crossref]

18. Kastrati A, Schömig A, Dirschinger J, Mehilli J, von Welser N, et al. (2000) Increased risk of restenosis after placement of gold-coated stents results of a randomized trial comparing gold-coated with uncoated steel stents in patients with coronary artery disease. Circulation 101: 2478-2483. [Crossref]

19. Edelman ER, Seifert P, Groothuis A, Morss A, Bornstein D, et al. (2001) Gold-coated NIR stents in porcine coronary arteries. Circulation 103: 429-434. [Crossref]
20. Nolan BW, Schermerhorn ML, Powell RJ, Rowell E, Fillinger MF, et al. (2005) Restenosis in gold-coated renal artery stents. J Vasc Surg 42: 40-46. [Crossref]

21. Shih CC, Shih CM, Chou KY, Lin SJ, Su YY (2007) Electrochemical and SEM characterization of gold-coated stents in vitro. J Electrochem Soc 154: C326-C330.

22. Möller H (2010) Contact allergy to gold as a model for clinical-experimental research. Contact Dermatitis 62: 193-200. [Crossref]

23. Ekqvist S, Svedman C, Lundh T, Möller H, Björk J, et al. (2008) A correlation found between gold concentration in blood and patch test reactions in patients with coronary stents. Contact Dermatitis 59: 137-142. [Crossref]

24. Prunotto M, Isaia C, Gatti M, Monari E, Pasquino E, et al. (2005) Nitinol Carbofilm coated stents for peripheral applications: study in the porcine model. J Mater Sci Mater Med 16: 1231-1238. [Crossref]

25. Antoniucci D, Bartorelli A, Valenti R, Montorsi P, Santoro GM, et al. (2000) Clinica and angiographic outcome after coronary arterial stenting with the carbostent. $\mathrm{Am} \mathrm{J}$ Cardiol 85: 821-825. [Crossref]

26. Colombo A, Airoldi F (2003) Passive coating: the dream does not come true. J Invasive Cardiol 15: 566-567. [Crossref]

27. Airoldi F, Colombo A, Tavano D, Stankovic G, Klugmann S, et al. (2004) Comparison of diamond-like carbon-coated stents versus uncoated stainless steel stents in coronary artery disease. Am J Cardiol 93: 474-477. [Crossref]

28. Sick PB, Gelbrich G, Kalnins U, Erglis A, Bonan R, et al. (2004) Comparison of early and late results of a Carbofilm-coated stent versus a pure high-grade stainless steel stent (the Carbostent-Trial). Am J Cardiol 93: 1351-1356. [Crossref]

29. Guidance for industry and FDA staff. Non-clinical engineering tests and recommended labeling for intravascular stents and associated delivery systems. Available at: http:// www.fda.gov/MedicalDevices/DeviceRegulationandGuidance/GuidanceDocuments/ ucm071863.htm. Accessed November 30, 2016.

30. ASTM F2129 (2001) Standard test method for conducting cyclic potentiodynamic polarization measurements to determine the corrosion susceptibility of small implant devices.

31. Mc Cafferty E (2005) Validation of corrosion rates measured by the Tafel extrapolation method. Corros Sci 47: 3202-3215.

Copyright: $\bigcirc 2020$ Navarro L. This is an open-access article distributed under the terms of the Creative Commons Attribution License, which permits unrestricted use, distribution, and reproduction in any medium, provided the original author and source are credited. 